\title{
Apuntes de actualidad: El desafío de construir ciudadanía digital
}

\author{
Entrevista a Andrea Urbas \\ Chicos.net, Argentina*
}

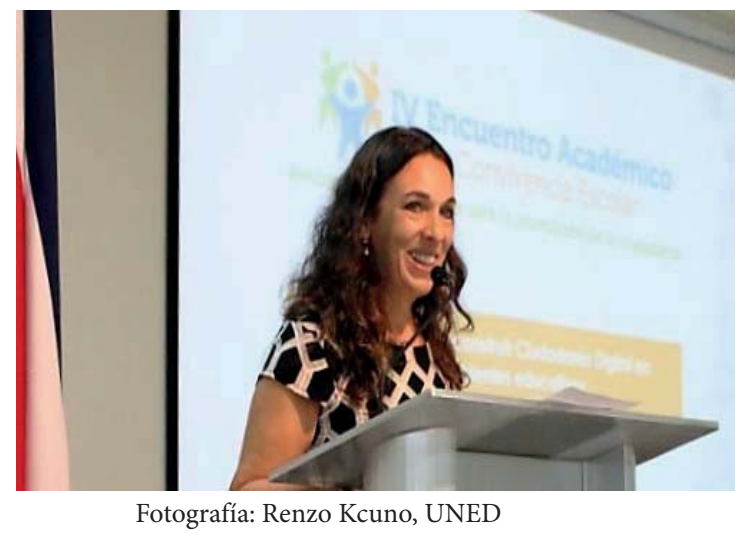

Andrea Urbas es Licenciada en Psicología de la Universidad de Buenos Aires, con especialidad en Organizaciones Sin Fines de Lucro, Universidad Di Tella- San Andrés. Es fundadora de la Asociación Chicos.net donde se desempeña como Directora de Programas. Diseña e implementa proyectos de capacitación, lidera equipos de trabajo, participa en publicaciones e investigaciones y coordina la Red Regional por el derecho de niños, niñas y adolescentes a un uso seguro y responsable de las TIC (RedNATIC). Participa en eventos nacionales y regionales.
Los días 13 y 14 de octubre del año 2016 se realizó en San José el IV Encuentro Académico sobre Convivencia Escolar: Ambientes conectados para la promoción de la ciudadanía. Esta actividad vincula a la Universidad Estatal a Distancia y la Fundación Omar Dengo con colaboradores estratégicos nacionales e internacionales. En esta oportunidad, se contó con la participación costarricense de la Fundación PANIAMOR y de Asociación Chicos.net de Argentina, representada por una de sus directoras, Andrea Urbas. 
esta forma, propician el pleno ejercicio de derechos en el ciberespacio por parte de los niños, niñas y adolescentes. Además, brindan capacitaciones a docentes de manera virtual y presencial. Se busca de esta manera, acompañar a la escuela en el ajuste a los cambios que impone la tecnología.

Gracias al equipo interdisciplinario que la compone, el abordaje se realiza desde diferentes miradas: educativa, psicológica, sociológica y antropológica.

Presentamos una síntesis de la entrevista realizada el día 12 de octubre del 2016.

¿Por qué es importante abordar el tema de tecnología con niños, niñas y adolescentes?

Porque ya no podemos separar el mundo físico del virtual: vivimos en un mundo que los integra. Esto es un poco difícil de entender y asumir para los adultos, quienes hemos crecido y encontrado la tecnología en el proceso, y no como la tienen ahora, chicos y chicas, naturalizadas, pero debemos adaptarnos.

Este nuevo mundo nos implica derechos y responsabilidades como ciudadanos digitales. Ahora, tener conectividad y acceso a las tecnologías es un derecho que se vincula con otros, como el derecho a educarse, a estar informados, el derecho a tener amigos y a pertenecer a un grupo, por ejemplo.

Es difícil para un chico quedar fuera de ciertas redes sociales o de ciertos espacios de socialización. La formación de la identidad se ve intervenida por el rol de las tecnologías, el disfrute y el uso pleno de los recursos digitales. Pero, ese espacio tiene reglas propias y características especiales, como el anonimato, o los cambios en la percepción del tiempo y el espacio. Todo esto construye lo que nosotros llamamos nuevas subjetividades: cambios a partir de estas nuevas lógicas de uso que definen cómo niños, niñas y adolescentes se presentan al mundo y a sus amigos.

Los padres estamos dando a los chicos herramientas tecnológicas muy tempranamente. Lo que dejamos de usar, lo que descartamos, se lo trasladamos a ellos. Niños y niñas están accediendo muy temprano a una Internet que es abierta (porque es muy poca la gente que pone Youtube con limitaciones para los más chicos). Por eso, les aparecen cosas en las pantallas que no buscan y los asustan, o que sí buscan cuando son más grandes, pero que son difíciles de procesar para ellos.

Esto se suma a que el nivel de consumo y uso tecnológico se acrecienta cada día y la hiperconexión alcanza no solo a chicos y chicas, sino también a los adultos en casa y en el centro educativo. El desconectarse no es fácil para nadie, sean chicos o adultos.

También, enfrentamos una situación delicada: las personas adultas no se ocupan del tema tecnológico porque creen que no saben, o que sus hijos o alumnos saben más que ellos. Percibimos un corrimiento del rol de cuidado del adulto cuando se trata de los medios tecnológicos. Sin embargo, es nuestra función acompañarles y cuando son más chicos hay que acompañarlos más aún. Muchos estudios lo demuestran. Por eso, hablamos de educación en relación al uso de las tecnologías.

\section{¿Qué es ciudadanía digital?}

La ciudadanía digital es un marco común de derechos y obligaciones para todos los usuarios de la tecnología como nuevo territorio, lo que implica la construcción conjunta de pautas de convivencia y de comportamiento en los entornos digitales. No es una noción limitada a los riesgos en Internet, sino que va más allá: hablamos de responsabilidad y compromiso, de derechos y obligaciones en los entornos digitales. 
La ciudadanía digital es un nuevo paradigma, una nueva lógica de uso para chicos y chicas, y es necesario transmitir que en esos espacios hay que aprender a convivir, que allí tiene que haber reglas de convivencia que deben construirse. Hay valores, principios y derechos que deben estar presentes en toda convivencia, y reconstruirse o resignificarse en los entornos virtuales con la participación de los chicos, incluyendo sus propios saberes y experiencias.

Se habla, entonces, de acompañar a niños, niñas y adolescentes porque las nuevas formas de relacionarse pasan por el filtro de la tecnología y se crean nuevos comportamientos, roles y pautas, además de riesgos...

Sí. Al crearse nuevas pautas, a las personas adultas nos corresponde acompañar y ayudar a diferenciar, por ejemplo, quiénes son amigos y quiénes son contactos, cómo hacemos para diferenciarlos...

Hay que repensar las tecnologías de modo crítico, dar un paso atrás para diferenciar y reflexionar sobre qué puedo publicar, qué es lo privado, lo público y lo íntimo. Son valores sobre los que hay que reflexionar. Esto nos toca a nosotros mismos como adultos usuarios de tecnología, ciudadanos digitales, porque también publicamos cosas que no son adecuadas, obviando nuestra "huella digital" (toda la información que vamos dejando en internet, por ejemplo: nombre, apellido y otros datos e imágenes e información importante sobre lo que hacemos, lo que "nos gusta" y compartimos, lo que pensamos, opinamos, nuestros contactos y conversaciones...). Hay que enseñarles a los niños a discernir, partiendo de nosotros mismos como adultos responsables.

Además, hay que mencionar los riesgos vinculados a las tecnologías, porque algunas de sus características (la posibilidad del anonimato, la globalidad, por ejemplo) incrementaron los delitos contra los menores. De estos, los más importantes son los relacionados con la vulneración de los chicos por adultos que buscan satisfacción sexual.

En el grooming, por ejemplo, el abuso sexual del pedófilo se hace a través de engaños y mentiras: buscan a los chicos en los perfiles, se hacen pasar por otros menores $y$, bajo engaño, logran apropiarse de sus imágenes o les inducen a hacer cosas frente a la cámara. ¡Pero esto no se da de un día para otro! Se genera un vínculo de confianza, en el que la mayoría de las veces el niño o la niña es engañado por el adulto para su propia satisfacción sexual o para pertenecer a redes de pedofilia.

Otra situación es la cantidad de pornografía con niños que circula, se vende, se consume en internet, generada especialmente en países donde hay mucha pobreza, chicos muy vulnerables y vulnerados.

También, en otro plano, está la violencia de los mismos chicos entre ellos, como el ciberbullying (bullying + tecnología), que tiene una potencia muy grande porque el afectado prácticamente no tiene espacio de descanso, porque las agresiones a través de los medios tecnológicos lo alcanzar en todo tiempo y lugar. Esta probemática debe trabajarse en la escuela, porque afecta la convivencia grupal. Debe ser tratado con intervenciones pedagógicas que involucren a todo el grupo de pares para desmontar la escena.

¿Cuál es el rol del centro educativo frente a la tecnología?

La escuela tiene una nueva tarea que no puede descuidar: educar para la convivencia también en contextos digitales. Lo que sucede en la web y fuera de la web es un continuo; no podemos pensar más en mundos separados. La escuela ya no es un espacio cerrado que separa lo que pasa fuera de ella, ese "adentro" y "afuera" ya no existe: las "paredes de la escuela" son permeables, "porosas", a lo que sucede fuera de ella. Son sus 
mismos alumnos los que tienen conflictos o situaciones en redes sociales.

Además, los chicos y las chicas vienen a la escuela con tecnologías y no las usan solo en la hora de informática y las escuelas no saben cómo lidiar con este tema: se les prohíbe, se les quita, se les deja, no saben cómo incorporarlas. Es imposible evitar el ingreso de la tecnología al centro educativo y el mundo escolar.

Por eso, nuestro trabajo desde Chicos.net no es con los profesores de Informática porque esto va más allá del manejo de herramientas digitales. Trabajamos con todos los docentes para tratar de minimizar las brechas digitales, generacionales y de uso. Impulsamos, además, la inclusión de la alfabetización digital y la construcción de ciudadanía digital en la formación profesional de los docentes, de todos, porque todas las asignaturas están atravesadas por las tecnologías y los usos que chicos y chicas hacen de ellas también para el trabajo escolar.

\section{Reflexiones finales}

Hay que dejar de hacer la diferenciación entre mundo virtual y real y asumir un mundo integrado, con características diferentes.

La importancia de dar espacios para el diálogo y la reflexión entre pares y con adultos pasa por mirarnos a nosotros mismos para ver cuáles son nuestras actitudes en casa, en la mesa, hasta que hora estamos conectados... Debemos dar el ejemplo, y abrir espacios para hablar y disfrutar con los chicos y las chicas desconectados de las pantallas.

También, se debe garantizar que los menores de edad estén protegidos con leyes adecuadas y sean alcanzados con programas educativos que los empoderen en el uso de la tecnología.

La participación es fundamental. Niños, niñas y adolescentes deben estar involucrados en la creación y la definición de las normas de convivencia de la escuela a la que asisten.

El uso sano, seguro y productivo de las tecnologías requiere que chicos y chicas se apropien, puedan encontrar los usos significativos, solidarios, productivos, pasando de consumidores a prosumidores (poder desarrollar sus propios productos y hacerlos visibles), y contribuyendo a mejorar la sociedad en la viven: a través de las redes se pueden sumar a causas sociales, pueden crear campañas, participar en discusiones y debates sobre temas que les preocupan e interesan, buscar información significativa, etc.

Creemos que los docentes pueden apoyar a potenciar estas oportunidades, y no estar excesivamente preocupados por controlar, limitar y prohibir. El incorporar la tecnología a la escuela ya no puede relegarse, el desarrollo y fortalecimiento de la ciudadanía digital es fundamental para formar ciudadanos plenos de derechos. 